\title{
The Effect of the Portland and Eco-cement Stabilization on the Physical and Mechanical Behaviour of the Bahlui Clay
}

\author{
Aniculaesi M. ${ }^{1, a}$, Stanciu A. ${ }^{1, b}$, Lungu I, \\ 1"Gheorghe Asachi” Technical University of lasi, Faculty of Civil Engineering and Building \\ Services, 43 D. Mangeron, 700050, Iași, Romania \\ a aniculaesi.mircea@gmail.com, b anghel.stanciu@yahoo.com, ' ilungu@ce.tuiasi.ro
}

Keywords: expansive clay, chemical stabilization, eco-cement, swell-shrinkage potential

\begin{abstract}
The research program developed by the authors and presented in this paper designate the Bahlui clay - Romania fitting the clays with specific behaviour such as the Addis Ababa clay, London clay, Dharwad clay, New Yorkshire clay, Ankara clay and Weald clay. Its behaviour is mainly characterized by high swells and shrinkages at moisture variations. The utilization of the Bahlui clay as good foundation soil or material for compacted soil cushion required the determination of the parameters characterizing its behaviour during moisture variation: swellshrinkage, compressibility and respectively shear strength. The research experiments to define the physical and mechanical behaviour of the Bahlui clay were performed on both natural and remoulded samples with $2.5 \div 10 \%$ mix from the dry soil mass with Portland with/or eco-cement. The paper presents graphs and tables displaying the Portland/eco-cement stabilization influence on the main physical and mechanical indices characterizing the Bahlui clay behaviour during moisture variations as well as conclusions its usage.
\end{abstract}

\section{Introduction}

Expansive soils have a high content of clay rich in montmorillonite and illite, as strong hydrophilic minerals, with the liquidity limit higher than $40 \%$ and the plasticity index higher than $20 \%$ and thus both of them more than those for regular/inactive clays [1].

Swell-shrinkage cycles due to moisture variations induce differential movements of the foundation soil, becoming the reason of many structural damages of constructions founded on expansive soils. Some approaches in foundations design on expansive clays are referring to the exceeding of the active zone and foundation anchorage with deep elements in the soil layer acting with reduced potential or totally inactive. Other frequently used approaches consider beneficial to excavate and remove the expansive soil zone and replace it with a cushion.

In this last approach category, the expansive clay is fully or partially replaced with a soil/material with no volume variations due to moisture variations. Using the soil transferred from another location to perform the cushion is possible as long as the distance from the construction site is not too large to prove the solution economically ineffective.

The chemical stabilization of the expansive clay from the construction site and incorporating the resulted material within the cushion is current practice, since the utilization of good or inactive soils to moisture variations is costly enough.

Katti (1979) [2] [3] suggests based on its own work, the use of certain variation limits of the geotechnical characteristics, correlated with the cushion thickness made of inactive soil. These restrictive values are presented in Table 1.

The reduction of the swell-shrinkage potential by chemical stabilization of the expansive clays can be obtained using in addition to soils various materials: lime, fly ash, Portland and eco-cements. Many research works focused on using waste based materials in stabilizing these soils. This research program carried out by the authors of this paper obtained results regarding the efficient use of some eco-cement made of the waste material from thermal power plants on the improvement of the physical and mechanical behaviour of the Bahlui clay - Romania. 
Table 1. Geotechnical parameters that need to be satisfied by the soil cushion material [3]

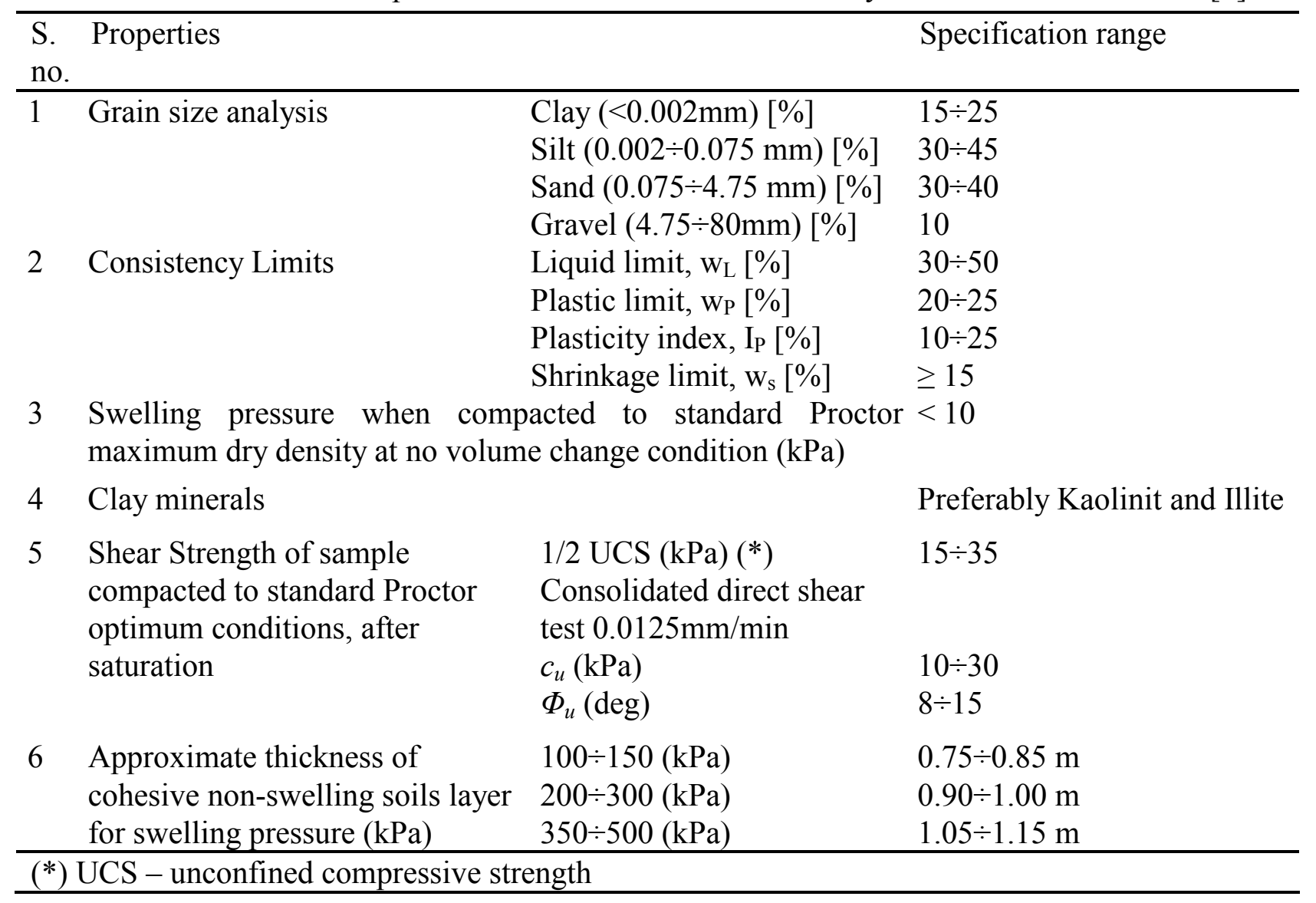

\section{Materials}

Soil. The expansive clay investigated in this study originated from the Bahlui river plain, from the city of Iasi - Romania. Its physical properties with comparative values characterizing other expansive clays worldwide are displayed in Table 2. Comparing the physical properties values from Table 2 it results that the variation range of each physical characteristic of the Bahlui clay is similar with those for the Addis Ababa clay -Ethiopia followed by the London clay - U.K.; Dharwad clay India; New Yorkshire clay - U.K.; Ankara clay - Turkey and Weald clay - U.K.

Table 2. Characteristic geotechnical values of expansive clays

\begin{tabular}{|c|c|c|c|c|c|c|c|}
\hline S. & Representative & Geotechn & al character & tics & & & References \\
\hline & clays & $\mathrm{w}_{\mathrm{L}}[\%]$ & $\mathrm{W}_{\mathrm{P}}[\%]$ & $\mathrm{I}_{\mathrm{P}}[\%]$ & $\mathrm{A}_{2 \mu}[\%]$ & $\mathrm{A}[\%]$ & \\
\hline 1 & $\begin{array}{l}\text { Bahlui clay- } \\
\text { Romania }\end{array}$ & $83 \div 98$ & $26 \div 31$ & $57 \div 67$ & $51 \div 87$ & $0.77 \div 1.12$ & [4] \\
\hline 2 & $\begin{array}{l}\text { London clay - } \\
\text { U.K. }\end{array}$ & $60 \div 95$ & $24 \div 30$ & $36 \div 65$ & $42 \div 64$ & $0.67 \div 1.25$ & {$[5,6,7,8]$} \\
\hline 3 & Weald clay-U.K. & $41 \div 82$ & $18 \div 31$ & $21 \div 51$ & $38 \div 74$ & $0.6 \div 0.7$ & {$[8,9,10]$} \\
\hline 4 & $\begin{array}{l}\text { New Yorkshire } \\
\text { clay - U.K. }\end{array}$ & $53 \div 70$ & $20 \div 29$ & $29 \div 41$ & $41 \div 70$ & $0.46 \div 0.72$ & [11] \\
\hline 5 & $\begin{array}{l}\text { Ankara clay - } \\
\text { Turkey }\end{array}$ & $64 \div 75$ & $25 \div 43$ & $29 \div 34$ & $39 \div 55$ & $056 \div 0.94$ & {$[12]$} \\
\hline 6 & $\begin{array}{l}\text { Addis Ababa clay - } \\
\text { Ethiopia }\end{array}$ & $100 \div 105$ & $40 \div 43$ & $58 \div 65$ & $57 \div 76$ & $0.42 \div 0.56$ & {$[13]$} \\
\hline 7 & $\begin{array}{l}\text { Dharwad clay - } \\
\text { India }\end{array}$ & $48.2 \div 72$ & $10.7 \div 23.2$ & $35 \div 45.2$ & $52 \div 59$ & $0.66 \div 0.81$ & [11] \\
\hline
\end{tabular}


According to the Unified Soil Classification System, the majority of the soil samples were inorganic clays of high plasticity $(\mathrm{CH})$, and highly compressible inorganic silt and organic clays (ML) (Fig. 1a). Based on the Van der Merwe's diagram, all clays exhibit high to very high swell potential (Fig.1b).

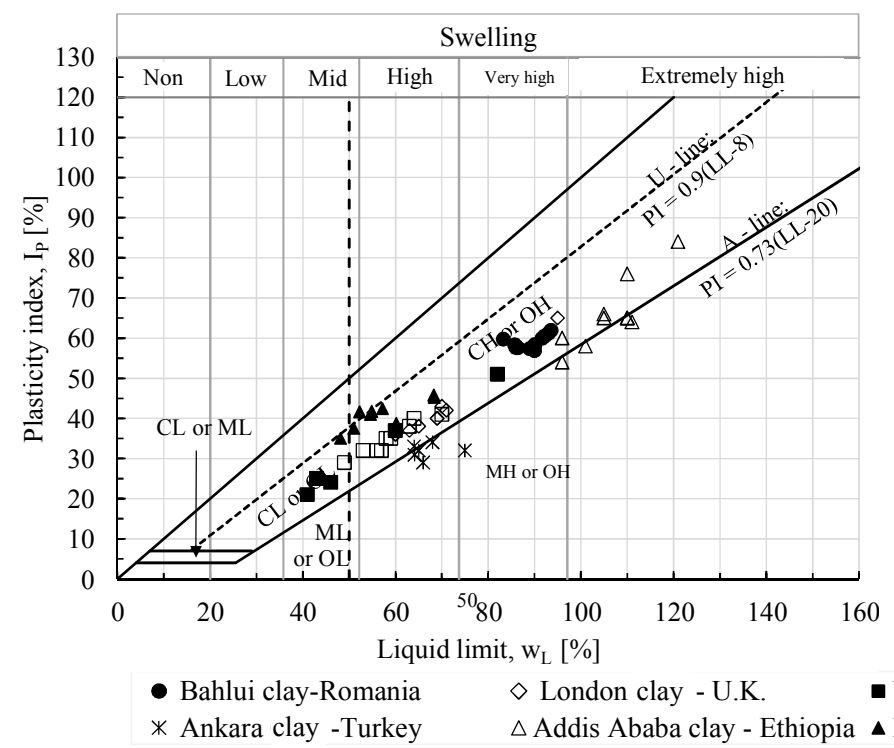

a)

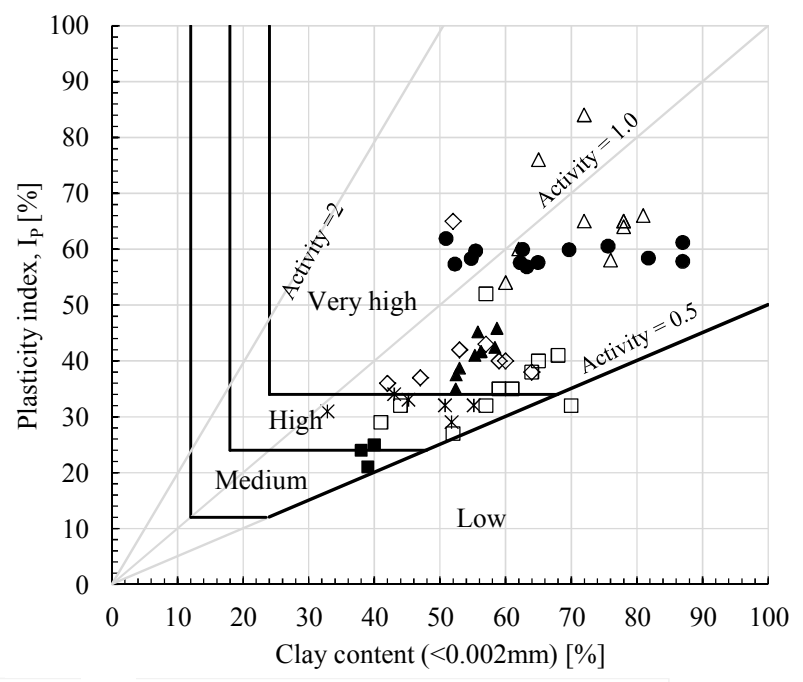

$\square$ New Yorkshire clay - U.K.

b)

Fig. 1. a) Unified Soil Classification System of the studied clay; and b) identification of swelling potential using the Van der Merwe chart.

Using these clays in natural state for a soil cushion would be inappropriate because of the high swell potential they posse on moisture variation.

Portland cement. The Portland cement (PC) used for this study has the chemical composition given in Table 3 and it was purchased in the regular construction materials market.

Eco-cement. Eco-cement has the chemical composition presented in Table 3 and it is made from a by-product of the production of iron in a blast furnace where iron ore, limestone and coke are heated to about $1500^{\circ} \mathrm{C}$ [14]. These two types of cement have the same chemical composition, but the proportion of the oxide compounds is different. By consequence, the rate of the eco-cement reaction with water is slower, and Portland cement is used as an activator. In this research work, the two cements, the Portland and the eco-cement are used in equal parts (1:1).

Table 3. The chemical composition of the hydraulic binders used in this research program

\begin{tabular}{lll}
\hline Oxide & Portland cement & Eco-cement \\
\hline $\mathrm{CaO}$ & $63 \%$ & $40 \%$ \\
$\mathrm{SiO}_{2}$ & $20 \%$ & $35 \%$ \\
$\mathrm{Al}_{2} \mathrm{O}_{3}$ & $6 \%$ & $10 \%$ \\
$\mathrm{MgO}$ & $2 \%$ & $8 \%$ \\
\hline Reference & {$[16]$} & {$[14]$} \\
\hline
\end{tabular}

Experimental program. The objective of this program is to reduce the swell potential of the Bahlui clay - Romania and to improve the behaviour of the stabilized soil as foundation soil, by analyzing comparatively the effect of the cement percentage increase (using both Portland cement as well as a 1:1 mix, Portland cement and eco-cement) for the chemical stabilization of this clay.

\section{Results and Discussion}

The influences of expansive clay Eco cement stabilization on the physical properties. The cement stabilization effect on the physical properties of the Bahlui clay has been studied in these two options (Portland cement stabilization and 1:1 mix of Portland and eco-cement stabilization). 
The binder content has been $0 \%, 2.5 \%, 5 \%, 7.5 \%$ and $10 \%$ of the dry soil mass. The obtained results for the grain size distribution, Atterberg limits and linear shrinkage are presented in Table 4. Diagrams in Figure $2 \mathrm{a} \div \mathrm{d}$ emphasize the effect of the Portland cement substitution as $50 \%$ with eco-cement as mix acting like binder in the Bahlui clay stabilization.

Table 4. The influence of the ecologic/Portland cements on the main geotechnical indices of the Bahlui clay-Romania

\begin{tabular}{llllllllll}
\hline $\begin{array}{l}\text { S. } \\
\text { no. }\end{array}$ & Mix & $\begin{array}{l}\mathrm{W}_{\mathrm{L}} \\
{[\%]}\end{array}$ & $\begin{array}{l}\text { Decrease } \\
\text { in } \mathrm{w}_{\mathrm{L}}[\%]\end{array}$ & $\begin{array}{l}\mathrm{I}_{\mathrm{P}} \\
{[\%]}\end{array}$ & $\begin{array}{l}\text { Decrease } \\
\text { in } \mathrm{I}_{\mathrm{P}}[\%]\end{array}$ & $\begin{array}{l}\mathrm{A}_{2 \mu} \\
{[\%]}\end{array}$ & $\begin{array}{l}\text { Decrease } \\
\text { in } \mathrm{A}_{2 \mu}[\%]\end{array}$ & $\begin{array}{l}\text { LS } \\
{[\%]}\end{array}$ & $\begin{array}{l}\text { Decrease } \\
\text { in LS [\%] }\end{array}$ \\
\hline 1 & Natural clay & 86.1 & - & 57.8 & - & 89 & - & 20.1 & 0 \\
2 & $2.5 \%(\mathrm{EC}+\mathrm{PC}) *$ & 86.2 & 0 & 41.9 & 27.51 & 63 & 29.21 & 19.4 & 3.48 \\
3 & $5 \%(\mathrm{EC}+\mathrm{PC}) *$ & 75.1 & 12.78 & 30.4 & 47.40 & 55 & 38.20 & 14.7 & 26.87 \\
4 & $7.5 \%(\mathrm{EC}+\mathrm{PC}) *$ & 75 & 12.89 & 30.8 & 46.71 & 48 & 46.07 & 14.3 & 28.85 \\
5 & $10 \%(\mathrm{EC}+\mathrm{PC}) *$ & 65.6 & 23.93 & 22.6 & 60.90 & 26 & 70.79 & 10.3 & 48.75 \\
6 & $2.5 \%(\mathrm{PC})$ & 88.3 & 0 & 52.8 & 8.65 & 78 & 12.36 & 20.8 & 0 \\
7 & $5 \%(\mathrm{PC})$ & 79.7 & 7.43 & 42.1 & 27.16 & 51 & 42.70 & 16.4 & 18.41 \\
8 & $7.5 \%(\mathrm{PC})$ & 69.6 & 19.16 & 25.1 & 56.57 & 47 & 47.19 & 15.0 & 25.37 \\
9 & $10 \%(\mathrm{PC})$ & 63.2 & 26.6 & 22.9 & 60.38 & 23 & 74.16 & 9.8 & 51.24 \\
\hline
\end{tabular}

$\mathrm{W}_{\mathrm{L}}$ - liquid limit; $\mathrm{I}_{\mathrm{P}}$ - plasticity index; $\mathrm{A}_{2 \mu^{-}}$colloidal clay fraction; $\mathrm{LS}$ - linear shrinkage;

(*) $50 \%$ eco-cement (EC) and 50\% Portland cement (PC)
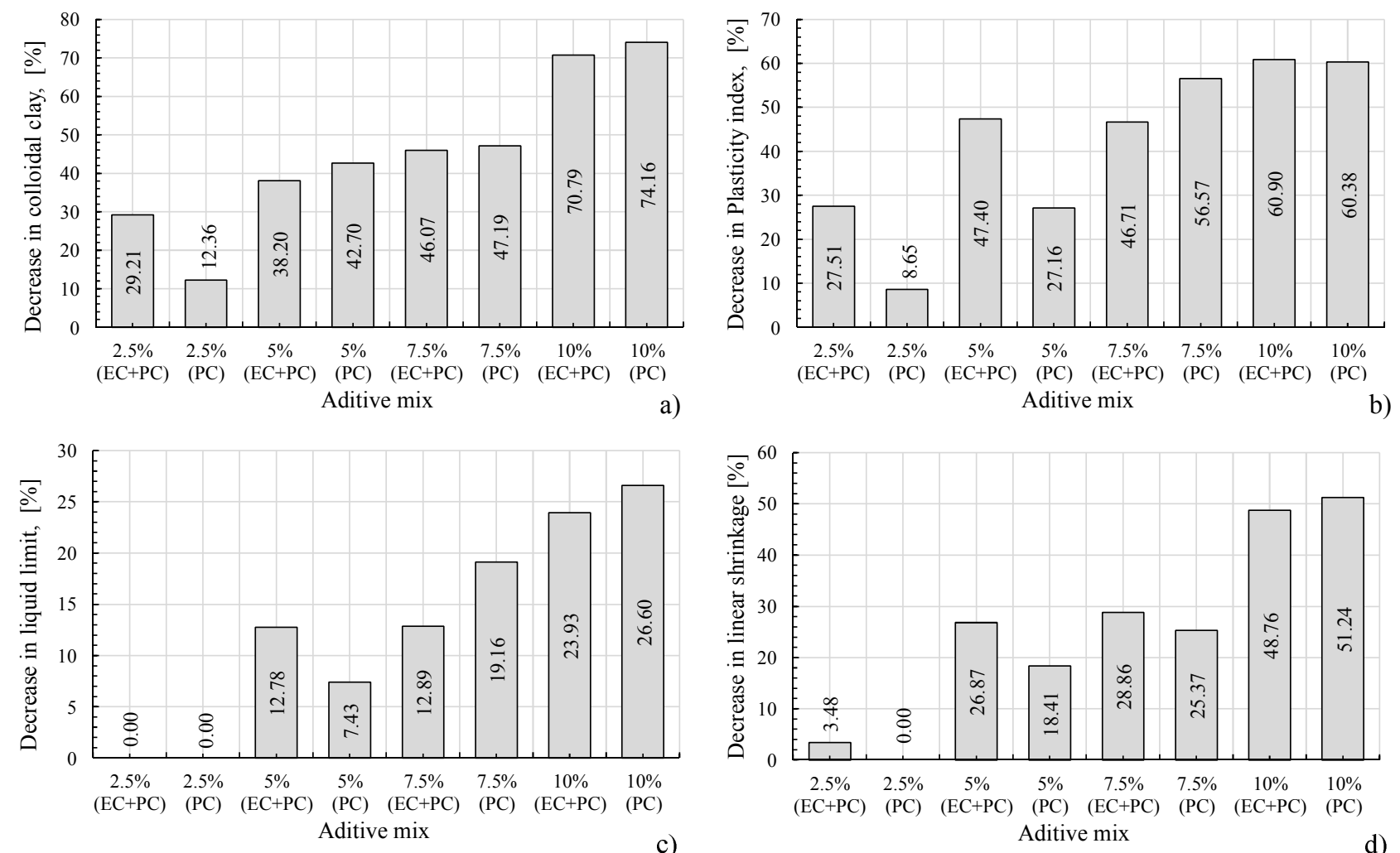

Fig. 2. Variation of the geotechnical indices with the chemical stabilizing agent

Figure $2 \mathrm{a} \div \mathrm{d}$ presents the percentage decrease of the geotechnical indices: liquid limit $\left(\mathrm{w}_{\mathrm{L}}\right)$, plasticity index $\left(I_{P}\right)$, colloidal clay fraction $\left(A_{2 \mu}\right)$ and linear shrinkage (LS) with the increase of the $\mathrm{PC}$ and $\mathrm{PC}+\mathrm{EC}$ mix.

The evaluation of the swell potential for the stabilized expansive soil is made indirectly based on the following geotechnical indices: liquid limit, plasticity index, colloidal clay fraction and linear shrinkage. Using this empirical correlation, the Bahlui clay - Romania develops a very high swell potential (Table 5). By the chemical stabilization of the Bahlui clay with Portland cement and 1:1 
mix of Portland and ecological cement, the swell potential is constantly decreased with the increase of the cement percentage, from very high for the natural clay to medium for $10 \%$ cement (PC or PC+EC mix). Van der Merwe [15] developed the correlation between the swell potential and heave per meter of the expansive (Table 5). Thus, the natural clay would display a heave of $80 \mathrm{~mm} / \mathrm{m}$ while being used as cushion material that can induce degradation for light structures founded on this soil without chemical stabilization. The Bahlui clay would reduce the potential heave from $80 \mathrm{~mm} / \mathrm{m}$ to $40 \mathrm{~mm} / \mathrm{m}$ by chemical stabilization with a binder mix of PC and EC.

Table 5. The swell potential of the stabilized Bahlui clay with Portland and eco-cement

\begin{tabular}{lllllll}
\hline \multicolumn{5}{c}{ Swell potential depending on } & Heave/meter of \\
S. no. & Mixes & $\mathrm{W}_{\mathrm{L}}[\%]$ & $\mathrm{I} P[\%]$ & $\mathrm{A}_{2 \mu}[\%]$ & LS [\%] & soil profile [mm] \\
\hline 1 & Natural clay & High & Very high & Very high & Very high & 80 \\
2 & $2.5 \%(\mathrm{EC}+\mathrm{PC}) *$ & High & Very high & Very high & High & 80 \\
3 & $5 \%(\mathrm{EC}+\mathrm{PC}) *$ & High & High & Very high & Medium & 40 \\
4 & $7.5 \%(\mathrm{EC}+\mathrm{PC}) *$ & High & High & Very high & Medium & 40 \\
5 & $10 \%(\mathrm{EC}+\mathrm{PC}) *$ & High & Medium & Medium & Low & 40 \\
6 & $2.5 \%(\mathrm{PC})$ & High & Very high & Very high & High & 80 \\
7 & $5 \%(\mathrm{PC})$ & High & Very high & Very high & Medium & 40 \\
8 & $7.5 \%(\mathrm{PC})$ & High & High & Very high & Medium & 40 \\
9 & $10 \%(\mathrm{PC})$ & High & Medium & Medium & Low & 40 \\
\hline
\end{tabular}

References: $\mathrm{w}_{\mathrm{L}}[17] ; \mathrm{I}_{\mathrm{P}}[18,19] ; \mathrm{A}_{2 \mu}[20] ; \mathrm{LS}[21] ;$ Heave/m meter of soil profile [15]

The requirements imposed for the soil cushion as values for the geotechnical indices presented in Table 1, are not fully satisfied by the chemical stabilization with cement (Portland cement (PC) and Eco-cement-Portland cement $(\mathrm{EC}+\mathrm{PC}))$. For $10 \%$ cement, for both cases of stabilization, with Portland cement and ecological/Portland cement mix, the colloidal clay content and the plasticity index decrease sufficiently to meet the requirements for a soil cushion (Table 1), but the other parameters, plastic limit and liquid limit develop still higher values than the demanded ones for the use of the material in cushion compaction (Table 1 and Table 4).

The influences of expansive clay Eco cement stabilization on the mechanical properties. The value increase of the shear strength parameters with the necessary binder addition for chemical stabilization can be designated to the initiated cation exchange by the chemical composition of the Portland and ecological cements. Clays consisting predominantly of montmorillonite present a residual internal friction angle decreasing with the increase of the liquid limit, approximated by the following function [22]:

$$
\tan \phi_{r}=22.26 \cdot w_{L}^{-1.094}
$$

where: $\Phi_{r}$ is the predicted value of the residual internal friction angle, $\mathrm{w}_{\mathrm{L}}-$ the liquid limit of the investigated clay (the correlation coefficient is $\mathrm{R}=0.837$ and it was determined using 142 soil samples). Using this correlation for the Bahlui clay both natural and stabilized with cement (PC and $\mathrm{PC}+\mathrm{EC}$ mix) one can notice (Table 6) an increase of the residual internal friction angle with the increase of the utilized cement. For percentages of $7.5 \%$ and $10 \%$ of PC, the stabilized clay will display higher values of the residual internal friction angle, by comparison with the $\mathrm{PC}+\mathrm{EC}$ binder mix.

Regarding the compressibility determined by oedometer laboratory tests and following the value of the compressibility index $\left(C_{c}\right.$ - Table 6$)$, the natural Bahlui clay displays a high compressibility $\left(C_{c}>0.4\right)$, while by stabilization with $10 \%$ cement $\mathrm{PC}$ and $\mathrm{PC}+\mathrm{EC}$ mix the compressibility decrease to medium $\left(C_{c}=0.2 \div 0.4\right)$. 
Table 6. The mechanical properties of the stabilized Bahlui clay with cement (PC and $\mathrm{EC}+\mathrm{PC})$

\begin{tabular}{|c|c|c|c|c|c|c|c|c|c|c|}
\hline \multirow{2}{*}{$\begin{array}{l}\text { S. } \\
\text { no. }\end{array}$} & \multirow{2}{*}{ Parameters } & \multirow{2}{*}{$\begin{array}{l}\text { Natural } \\
\text { clay }\end{array}$} & \multicolumn{4}{|c|}{$(\mathrm{EC}+\mathrm{PC})$ stabilization } & \multicolumn{4}{|c|}{ PC stabilization } \\
\hline & & & $2.5 \%$ & $5 \%$ & $7.5 \%$ & $10 \%$ & $2.5 \%$ & $5 \%$ & $7.5 \%$ & $10 \%$ \\
\hline 1 & $\Phi_{r}\left[{ }^{0}\right]$ & 9.65 & 9.64 & 11.17 & 11.19 & 12.9 & 9.39 & 10.48 & 12.11 & 13.41 \\
\hline 2 & $C_{c}$ & 0.573 & 0.54 & 0.457 & 0.424 & 0.385 & 0.552 & 0.498 & 0.456 & 0.399 \\
\hline
\end{tabular}

$\Phi_{r}$ - residual friction angle; $C_{c}$ - compression index; EC - eco-cement; PC- Portland cement

Swelling properties of treated expansive soil. The literature presents correlation techniques of the geotechnical properties indices to obtain an estimation of the swell potential $S$ and the swell pressure $P_{s}[19]$.

Eq. 2 is proposed for the swell pressure and Eq. 3 for the swell potential, both obtained by the method of least squares applied on the results from the laboratory tests, with a very high coefficient of correlation, $\mathrm{R}$, of the fitted regression lines $(\mathrm{R}>0.8)[23]$ :

$$
P_{S}=\left(6.9820 \cdot 10^{-4}\right) \cdot\left(I_{p}\right)^{1.92} \cdot \frac{A_{2 \mu}^{2}}{w_{i}^{2}}+9.1191
$$

where: $P s$ is the predicted value of the swell potential in psi, utilizing the initial value of the moisture content for the soil sample, $w_{i}$.

$$
S=\left(4.4938 \cdot 10^{-3}\right) \cdot\left(I_{p}\right)^{1.74} \cdot \frac{A_{2 \mu}}{w_{i}}+14.722
$$

in which: $S$ is the predicted value of the swell potential, expressed as percentage, using the natural moisture content of the soil sample $w_{i}$.

The predicted swell pressure for the natural Bahlui clay using the equation (2) resulted in $P_{s}=$ $177.85 \mathrm{kPa}$, which is approximately the same value obtained by oedometer tests performed according to ASTM D 4546-90, method A, $P_{s}=187 \mathrm{kPa}$.

The swell pressure and swell potential values for the stabilized Bahlui clay with $2.5 \% \div 10 \% \mathrm{PC}$ and $\mathrm{PC}+\mathrm{EC}$ mix are presented in Table 7.

The $75 \%$ decrease of the swell pressure $\left(P_{s}\right)$ (Table 7) for only $2.5 \% \mathrm{EC}+\mathrm{PC}$ cement mix or just $\mathrm{PC}$, continues at a smaller rate with the increase of cement participation to the stabilization process, recording decreases up to $10 \%$ for $10 \%$ cement percentage.

Table 7. The swelling potential of the stabilized Bahlui clay with Portland and eco-cement

\begin{tabular}{llllll}
\hline $\begin{array}{l}\text { S. } \\
\text { no. }\end{array}$ & Mixes & $\begin{array}{l}\text { Swell potential } \\
(\mathrm{S})[\%]\end{array}$ & $\begin{array}{l}\text { Decrease in swell } \\
\text { potential }[\%]\end{array}$ & $\begin{array}{l}\text { Swell pressure } \\
\left(\mathrm{P}_{\mathrm{s}}\right)[\mathrm{kPa}]\end{array}$ & $\begin{array}{l}\text { Decrease in swell } \\
\text { pressure }[\%]\end{array}$ \\
\hline 1 & Natural clay & 31.16465 & - & 177.85 & - \\
2 & $2.5 \%(\mathrm{EC}+\mathrm{PC}) *$ & 18.97018 & 39.12917 & 75.55118 & 57.51973 \\
3 & $5 \%(\mathrm{EC}+\mathrm{PC}) *$ & 16.82514 & 46.01208 & 67.99937 & 61.7659 \\
4 & $7.5 \%(\mathrm{EC}+\mathrm{PC}) *$ & 16.62094 & 46.66733 & 66.96804 & 62.34578 \\
5 & $10 \%(\mathrm{EC}+\mathrm{PC}) *$ & 15.33897 & 50.78085 & 63.57446 & 64.25389 \\
6 & $2.5 \%(\mathrm{PC})$ & 24.53638 & 21.26854 & 110.0464 & 38.12403 \\
7 & $5 \%(\mathrm{PC})$ & 18.80752 & 39.65112 & 74.51216 & 58.10394 \\
8 & $7.5 \%(\mathrm{PC})$ & 16.01555 & 48.60987 & 65.48824 & 63.17783 \\
9 & $10 \%(\mathrm{PC})$ & 15.31787 & 50.84858 & 63.51405 & 64.28786 \\
\hline
\end{tabular}

$\mathrm{S}$ - Swell potential; $\mathrm{P}_{\mathrm{s}}-$ Swell pressure $\mathrm{kPa} ;\left(^{*}\right) 50 \%$ eco-cement $(\mathrm{EC})+50 \%$ Portland cement $(\mathrm{PC})$

The initial moisture content of the soil $\left(w_{i}\right)$ plays an important role in the estimation of the swell pressure. In Figure $4 \mathrm{a} \div \mathrm{d}$ the variations of the swell pressure and swell potential are presented depending on the natural moisture content of the soil. 

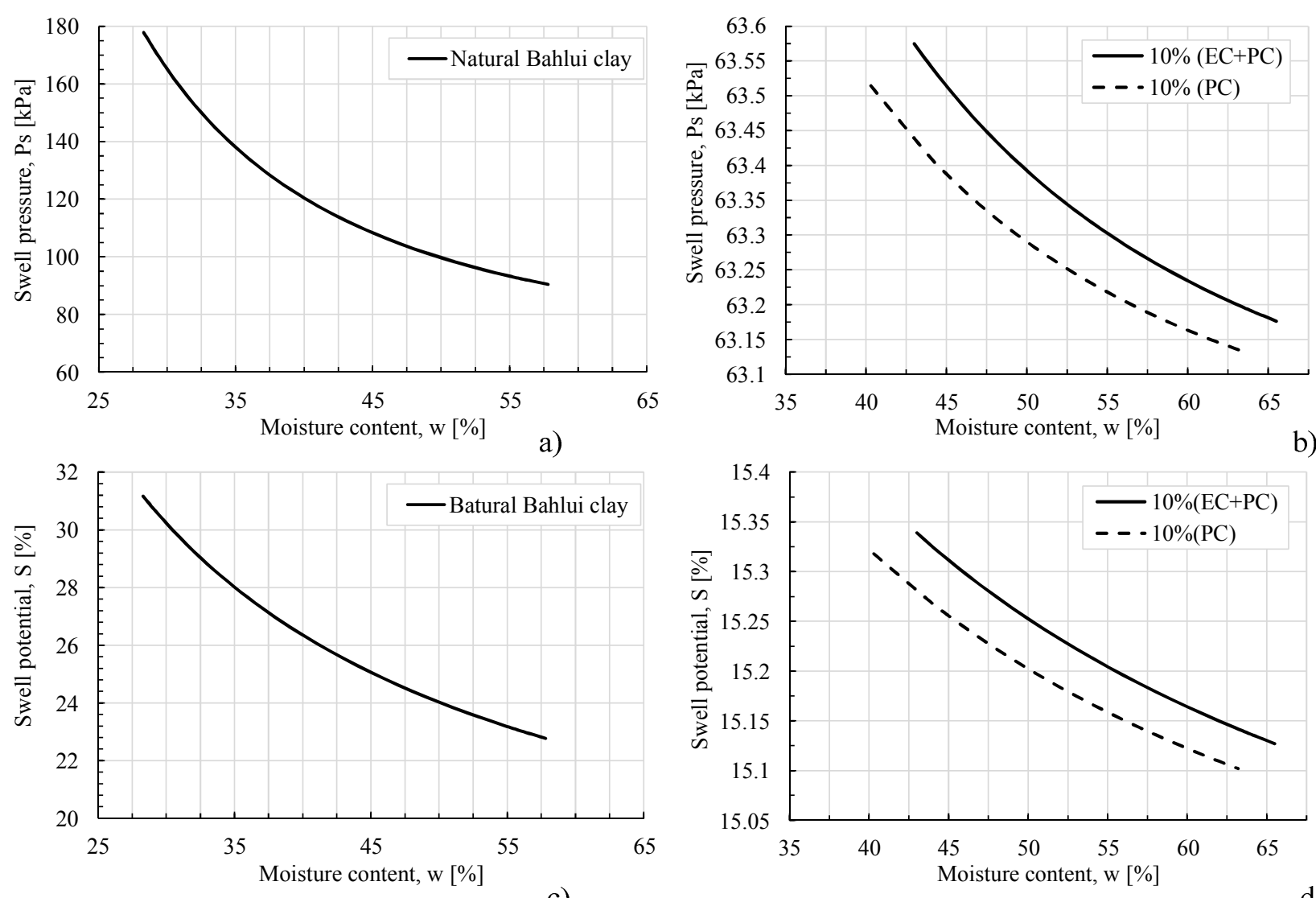

Fig. 3. Variations of a), b) swelling pressure and c), d) swelling potential, with the moisture content, for the Bahlui clay - Romania

\section{Conclusions}

The Bahlui clay - Romania is spread on a relatively large zone within the city of Iasi area. Founding construction on this clay as well as its utilization as material for soil cushions required the necessity to develop an extensive research program to obtain its main physical and mechanical properties. This research work performed by the authors classified this clay as being an expansive one, similar with other representative clays in the world (Addis Ababa clay - Ethiopia, London clay - U.K.; Dharwad clay -India; New Yorkshire clay - U.K.; Ankara clay - Turkey and the Weald clay from the U.K.). The Bahlui clay has been investigated to build without any structural risk exposure, establishing its behaviour and potential improvement based on the physical and mechanical characteristics, by chemical stabilization with Portland cement or cement mix, Portland and ecocement. It is noted based on the laboratory test results that stabilization by $10 \%$ cement (PC and $\mathrm{PC}+\mathrm{EC}$ mix) reduces the swell potential from very high to medium.

The very high swell pressure of the natural Bahlui clay $(177.85 \mathrm{kPa})$ decreases as well by $57.52 \%$ for only $2.5 \%$ cement (PC+EC mix) and with only $38.12 \%$ for $2.5 \%$ stabilization with Portland cement (PC). The influence of the eco-cement participation in the binder mix utilized in the stabilization is more pronounced at small values (up to $2.5 \%$ ) while the increase from $2.5 \%$ to $10 \%$ cement is not providing significant decreases of the swell pressure and swell potential. The partial substitution of the Portland cement with eco-cement lead to a significant influence on the environment protection by consequence of the reduction of non-renewable resources and $\mathrm{CO}_{2}$ emissions resulted from the manufacturing process. 
ACKNOWLEDGMENT: This paper was supported by the project "Development and support of multidisciplinary postdoctoral programmes in major technical areas of national strategy of Research - Development - Innovation" 4D-POSTDOC, contract no. POSDRU/89/1.5/S/52603, project cofunded by the European Social Fund through Sectoral Operational Programme Human Resources Development 2007-2013.

ACKNOWLEDGMENT: Thank to ECOCEM Ireland, for the eco-cement support provided during the research study.

\section{References}

[1] Shah Kinjal, A.K. Desai, C.H. Solanki, Experimental Study On The Atterberg Limits Of Expansive Soil Reinforced With Polyester Triangular Fibres, International Journal of Engineering Research and Applications (IJERA) Vol. 2, Issue 4, (2012) pp.636-639.

[2] R.K. Katti, Search for solution to problems in black cotton soils, Indian Geotechnics J 9(1)-80, (1979).

[3] P.S. Jagadish, K.P. Pradip, Effect of lime stabilized soil cushion on strength behaviour of expansive soil, Springer Science + Business Media B.V. (2010).

[4] N. Boti, Contributions on studying the shrinkage soils from the foundation ground in the Iasi city area, Doctoral Thesis, Polytechnic Institute „Gh. Asachi” Iasi, (1974) (in Romanian).

[5] A. Gasparre, Advanced laboratory characterization of London clay, Thesis submitted to University of London in partial fulfilment for the degree of Doctor of Philosophy and for the Diploma of Imperial College London (2005).

[6] Abu Siddique, C.R.I. Clayton, Mechanical properties of reconstituted soft London clay, Journal of Civil Engineering, The Institution of Engineers, Bangladesh, (1999) Vol. CE 27, No.1.

[7] D.M. Wood, Soil Behaviour and Critical State Soil Mechanics, Cambridge University Press, 1991.

[8] American Society of Civil Engineers, A History of Progress: Selected U.S. Papers in Geotechnical Engineering, (2003).

[9] F.K. Al-Gahtani, The influence of shearing on consolidated drained triaxial test strength characteristics, Submitted in Partial Fulfilment of the Requirement for the degree of Bachelor of Science in Civil Engineering in the College of Engineering, February (2007).

[10] T.W. Lambe, R.V. Whitman, Soil Mechanics, John Wiley and Sons, Inc., NY, USA, 1969.

[11] U.D. Hakari, S.C. Puranik, Evaluation of Swell Potential and Identification of Expansive and Problematic Soils in Civil Engineering Works by Newly Developed Matrices Based on Index and Grain Size Properties, EJGE, Vol. 15 (2010) pp. 1712-1726.

[12] Amer Ali Al-Rawas, F.A. Mattheus, Expansive Soils: Recent Advances in Characterization and Treatment, Taylor \& Francis, 2006.

[13] W. Ahmed, Contrast in clay mineralogy and their effect on reservoir properties in sandstone formations, Bull. Chem. Soc. Ethiop. (2008), 22(1), 41-65.

[14] Information on http://www.ecocem.ie: Ecocem (GGBS) cement

[15] D.H. Van der Merwe, The Prediction of Heave from the Plasticity Index and Clay Fraction of Soils, Proceedings of the South African Institution of Civil Engineers (1964).

[16] W. Czernin, Cement Chemistry and Physics for Civil Engineers, Crosby Lockwood, London 1962. 
[17] D.R. Snethen, Evaluation of expedient methods for identification and classification of potentially expansive soils. Proceedings, 5th International Conference on Expansive soils, Adelaide, (1984) pp. 22-26.

[18] V. Raman, Identifications of expansive soils from Plasticity index and the shrinkage index data. The Indian Engineer 11(1), (1967) pp. 17-22.

[19] F.H. Chen, Foundations on Expansive soils. Elsevier, Amsterdam, 1988.

[20] W.G. Holtz, Expansive clay - properties and problems. Journal of the Colorado School of Mines (1959) 54 (4), pp. 89-125.

[21] J.J. Mills, B.W. Murphy, H.G. Wickham, A study of simple laboratory tests for the prediction of soil shrink-swell behaviour, Journal of the Soil Conservation Service, New South Wales, Sidney (1980).

[22] M. Suzuki, S. Tsuzuki, T. Yamamoto, Physical and Chemical Index Properties of Residual Strength of Various Soils; Memoirs of the Faculty of Engineering Yamaguchi University (2005), Vol.56 No.1.

[23] N.V. Nayak, R.W. Christensen, Swelling characteristics of compacted, expansive soils, Clays and Clay Minerals, Vol. 19, (1971) pp. 251-261. 